\title{
A New Approach for Training Needs Assessment
}

\author{
Bahgat M. Abdel-Maksoud1*, Samir Saknidy² \\ ${ }^{1}$ Faculty of Agriculture, Assiut University, Assiut, Egypt \\ ${ }^{2}$ Faculty of Science, Assiut University, Assiut, Egypt \\ Email: "bahgat.abdelmaksoud@yahoo.com, "maksoud43@aun.edu.eg, samirsaknidy@gmail.com
}

Received 30 March 2016; accepted 14 June 2016; published 17 June 2016

Copyright (C) 2016 by authors and Scientific Research Publishing Inc.

This work is licensed under the Creative Commons Attribution International License (CC BY).

http://creativecommons.org/licenses/by/4.0/

c) (i) Open Access

\begin{abstract}
This paper reviews quantitative methods for educational and training needs assessment. The paper introduces a new simple approach for this purpose. The approach does not resort to the probability theory. Collected data as two bivariate distributions are tabulated using a five point Likert type scale. A proposed linear cell-weight is applied to each cell. A distribution index is proposed for measuring educational and training needs. The introduced scale is simple, positive, and finite (runs from 0 - 1). The technique is applied on data gathered locally. It contributes in education/training needs assessment methods in the field of education and extension education.
\end{abstract}

\section{Keywords}

Borich Model, Cell Weight, Delta N, Modified Delta N, Needs Assessment, Weighted Total Index

\section{Introduction and Objectives}

Needs assessment as a process of identifying needs and placing them in some order of priority is crucial for successful education/training programs. There are several qualitative/quantitative methods and techniques for educational and training needs assessment. Each has its advantages and disadvantages. It is recommended to use multiple methods for needs assessment as to balance the strengths and limitations of each [1].

Our focus here is on quantitative methods. These methods depend mainly on data collected using questionnaires from respondents on their evaluation of the degree of importance of certain subjects and their level of knowledge of these subjects. Such data are collected using a five point Likert type scale ranging from one (very low) to five (very high) for knowledge, and from one (not important) to five (very important) for importance. The following quantitative methods are used for training needs: average degree of importance, average level of

${ }^{*}$ Corresponding author. 
knowledge, discrepancy between importance and knowledge, and the use of $2 \times 2$ arrays between importance and knowledge identified by Hershowitz in 1973 [2].

The first equation used for training needs assessment was introduced by Borich in 1980 [3] by relating importance and knowledge in the form of the following empirical equation:

Training Need $=($ Importance - Knowledge $) \times$ Mean Importance .

Assigning a value of one for the very low level and a value of five for the very high level, the scale of Borich model will range from -20 to +20 .

Misanchuk in 1984 [4] devised the Delta N method. He used the 5 by 5 array of respondents' evaluation of the degree of importance of certain subjects and their level of knowledge of these subjects. In his work, Misanchuk introduced the following equation for computing Delta N:

where:

$$
\text { Delta } \mathrm{N}=1-\frac{\sum_{i=1}^{R} \sum_{j=1}^{C} W_{i j} P_{i j}}{\sum_{i=1}^{R} \sum_{j=1}^{C} W_{i j} P_{i} P_{j}}
$$

$R_{i}$ : Refers to rows from $i=1$ to 5 .

$C_{j}$ : Refers to columns from $j=1$ to 5 .

$W_{i j}$ : The error weight for cell $(i, j)$.

$P_{i j}$ : The probability of a randomly sampled observation falling into cell $(i, j)$.

$P_{i}$ and $P_{j}$ : The expected marginal probabilities for rows $\left(R_{i}\right)$ and columns $\left(C_{j}\right)$ respectively.

Misanchuk suggested what he called "error weights" for the distribution cell and assumed some probability distribution of the marginal values (flat, normal, and monotonic values). He stated "Del can assume a range of values from minus infinity to 1" [4]. The lower limit (if one is to take minus infinity as a limit) occurs if the denominator would be zero. If on the other hand the numerator is zero, one gets the upper limit. The scale is not finite.

To overcome this difficulty, Abdel-Maksoud in 2010 [5] developed a modified version of Delta $\mathrm{N}$ by equating the denominator to one, and used the following equation:

$$
\text { The Modified Delta } \mathrm{N}=1-\sum_{i=1}^{R} \sum_{j=1}^{C} W_{i j} P_{i j}
$$

The difference between the two equations in application is not great as long as the denominator is not far from unity. The scale in the modified version is finite and positive (between 0 and 1). For detailed description of the calculations of Delta $\mathrm{N}$ and the modified Delta N methods, the reader is referred to Misanchuk [4] and [6] and Abdel-Maksoud [5].

The objective of the present work is to introduce a systematic approach based on statistical methods to the assessment as opposed to the intuitive approach. We shall not resort to the probability theory [7]. The new proposed approach is based on identifying weights for cells instead of "error weights" suggested by Misanchuk. Our new approach also does not assume any kind of probability distribution of marginal values. The new method is then applied on actual data.

This paper is divided into four sections. The above introduction \& objectives is the first section. The second deals with the development of the new proposed approach. The third section includes an empirical study on locally collected data. Finally, the fourth section is the conclusion.

\section{The Development of the New Approach}

To describe our proposed technique, we first identify weights for cells, find an index for the distribution, and give some examples for demonstration.

\section{Cell Weight}

It is logical to say that the highest need value is that for the case of very high importance coupled with very low knowledge. This means the right upper side of the table. As stated by Misanchuck, "It is reasonable to say that the highest need exists for that skill in which all respondents show a great lack of competence coupled with a 
high job relevance, i.e., all respondents fall into cell $(1,5)$ " [4]. Of course; the situation is the reverse for the cell $(5,1)$.

To explain the situation more clearly: Suppose that all respondents fall into one of the four corner cells $\{(1,1)$, $(1,5),(5,1)$, or $(5,5)\}$. Without any added value to each cell; the 4 situations would be equal. This shows clearly the need for weighing the cells. If the cell $(1,5)$ is to be weighted to unity, then the $(5,1)$ cell is supposed to be weighted to zero. So, we assign a number to each cell in a decreasing order from the cell $(1,5)$ as the hub of the decreasing contours.

The proposed 2-dimensional weight values scale is a linear one. Of course; any other scale (logarithmic for example or any nonlinear scale) will do as well. The proposed weight of each cell is shown in Table 1. So, we are to multiply each cell's obtained data value by its proposed weight. The result "Weighted array" is the one we deal with from now on.

\section{Distribution Index}

The logical step now is to find an index for the weighted data that can be taken as a measure of training needs. We propose the following index.

The Weighted Total Index or the Array Index $=\sum$ weighted total $\div$ total number of respondents. The application of the idea to hypothetical data is shown in Table 2.

The Weighted Total Index or the Array Index $=24.5 \div 45=0.544$.

The procedure of our proposed technique can be summarized in the following steps:

a. Data tabulated as bivariate tables.

b. The data are then treated to the weight factor.

c. The Distribution Index (The Weighted Total Index) is then calculated.

Table 1. Proposed linear weight factor scale.

\begin{tabular}{ccccccc}
\hline \multirow{2}{*}{ Knowledge } & \multicolumn{5}{c}{ Importance } \\
\cline { 2 - 6 } & 1 & 2 & 3 & 4 & 5 \\
\hline 1 & 0.500 & 0.625 & 0.750 & 0.875 & 0.000 & 0.875 \\
2 & 0.375 & 0.500 & 0.625 & 0.750 & 0.750 \\
3 & 0.250 & 0.375 & 0.500 & 0.625 & 0.625 \\
4 & 0.125 & 0.250 & 0.375 & 0.500 & 0.375 & 0.500 \\
\hline
\end{tabular}

Table 2. Hypothetical data as an illustrative example*.

\begin{tabular}{|c|c|c|c|c|c|c|}
\hline \multirow{2}{*}{ Knowledge } & \multicolumn{5}{|c|}{ Importance } & \multirow{2}{*}{ Total } \\
\hline & 1 & 2 & 3 & 4 & 5 & \\
\hline 1 & $\begin{array}{c}1 \\
0.500\end{array}$ & $\begin{array}{c}1 \\
0.625\end{array}$ & $\begin{array}{c}1 \\
0.750\end{array}$ & $\begin{array}{c}1 \\
0.875\end{array}$ & $\begin{array}{c}1 \\
1.000\end{array}$ & $\begin{array}{c}5 \\
3.750\end{array}$ \\
\hline 2 & $\begin{array}{c}1 \\
0.375\end{array}$ & $\begin{array}{c}1 \\
0.500\end{array}$ & $\begin{array}{c}2 \\
1.250\end{array}$ & $\begin{array}{c}3 \\
2.250\end{array}$ & $\begin{array}{c}2 \\
1.750\end{array}$ & $\begin{array}{c}9 \\
6.125\end{array}$ \\
\hline 3 & $\begin{array}{c}1 \\
0.250\end{array}$ & $\begin{array}{c}1 \\
0.375\end{array}$ & $\begin{array}{c}3 \\
1.500\end{array}$ & $\begin{array}{c}7 \\
4.375\end{array}$ & $\begin{array}{c}2 \\
1.500\end{array}$ & $\begin{array}{c}14 \\
8.000\end{array}$ \\
\hline 4 & $\begin{array}{c}1 \\
0.125\end{array}$ & $\begin{array}{c}1 \\
0.250\end{array}$ & $\begin{array}{c}2 \\
0.750\end{array}$ & $\begin{array}{c}3 \\
1.500\end{array}$ & $\begin{array}{c}3 \\
1.875\end{array}$ & $\begin{array}{c}10 \\
4.500\end{array}$ \\
\hline 5 & $\begin{array}{c}1 \\
0.000\end{array}$ & $\begin{array}{c}1 \\
0.125\end{array}$ & $\begin{array}{c}1 \\
0.250\end{array}$ & $\begin{array}{c}2 \\
0.750\end{array}$ & $\begin{array}{c}2 \\
1.000\end{array}$ & $\begin{array}{c}7 \\
2.125\end{array}$ \\
\hline Total & $\begin{array}{c}5 \\
1.250\end{array}$ & $\begin{array}{c}5 \\
1.875\end{array}$ & $\begin{array}{c}9 \\
4.500\end{array}$ & $\begin{array}{c}16 \\
9.750\end{array}$ & $\begin{array}{c}10 \\
7.125\end{array}$ & $\begin{array}{c}45 \\
24.500\end{array}$ \\
\hline
\end{tabular}

*In each cell: the upper figure is the number of respondents falling in the cell, and the lower figure is the weighted value of the cell (the number of respondents multiplied by the cell weight). 
d. According to the indices obtained for different subjects, the most crucial needs can be determined and training or educational programs can be effectively designed and implemented.

It seems reasonable to deal briefly with the above example given in Table 2. Recall Misanchuk equation and the Modified Delta N equation from the introduction section and applying these two equations and our proposed technique on these data using a so-called "error factor" (Table 3) instead of Misanchuk suggested error weights (Table 4). The reader would notice that this is the transpose of our linear weight factor table proposed in Table 1. This application revealed at the following results:

Delta N (Flat rate of marginal distributions) $=0.043$.

The Modified Delta $\mathrm{N}=0.5444$.

Weighted Total Index (New Approach) $=0.5444$.

It is to be noticed that the weigh factor and the error factor (weight factor transpose) are two complementary values which if added together will equal unity. Thus

The Weighted Total Index $=$ The Modified Delta $\mathrm{N}=1-\sum_{i=1}^{R} \sum_{j=1}^{C} W_{i j} P_{i j}$.

The last expression is the one Introduced by Abdel-Maksoud (2010).

\section{The Empirical Study}

A survey was carried out on staff members holding PhD of the faculty of agriculture, Assiut University, Egypt where the first author works. A questionnaire form was prepared to collect necessary data for this study. Questionnaires were distributed among staff members of the faculty by hands either directly or through heads of all departments of the faculty. The number of completed returns was 100 or $39 \%$ of the total number of staff members which was estimated to be 257 members at the time of data collection (2014). The questionnaire form included data on personal and professional characteristics of respondents, and their evaluation of the degree of importance and their level of competence of using seven educational technologies. The data concerning respondents' evaluation of the degree of importance of educational technologies and their level of competence were

Table 3. Proposed linear error factor scale (Table 1 Transpose).

\begin{tabular}{ccccccc}
\hline \multirow{2}{*}{ Knowledge } & \multicolumn{5}{c}{ Importance } \\
\cline { 2 - 6 } & 1 & 2 & 3 & 4 & 5 \\
\hline 1 & 0.500 & 0.375 & 0.250 & 0.125 & 000 & 0.125 \\
2 & 0.625 & 0.500 & 0.375 & 0.250 & 0.250 & 0.375 \\
3 & 0.750 & 0.625 & 0.500 & 0.500 & 0.500 \\
\hline
\end{tabular}

Source: (Table 2 Transpose)

Table 4. Misanchuk suggested error weights for computing Delta N.

\begin{tabular}{ccccccc}
\hline \multirow{2}{*}{ Knowledge } & \multicolumn{5}{c}{ Importance } & \multicolumn{1}{c}{. } \\
\cline { 2 - 6 } & 1 & 2 & 3 & 0.1768 & 0.000 \\
\hline 1 & 0.7071 & 0.5303 & 0.3536 & 0.2500 & 0.1768 \\
2 & 0.7289 & 0.5590 & 0.3953 & 0.3953 & 0.3536 \\
3 & 0.7906 & 0.6374 & 0.500 & 0.5590 & 0.5303 \\
5 & 0.8839 & 0.7500 & 0.6374 & 0.7289 & 0.7071 \\
\hline
\end{tabular}

Source: Misanchuk, 1984 [4]. 
gathered using a Likert type five point scale ranging from not important to very important for the degree of importance and from very low to very high for the level of competence. These data were completed only by 67 members. Accordingly, training needs were assessed for these members only. We applied our proposed new approach and previous methods and techniques for training needs assessment on the collected data. A summary of the results of these computations is given in Table 5. These results include the final indices obtained for training needs for respondents for the seven educational technologies included in this study.

\section{Discussion}

The indices obtained from the application of our new approach and the modified Delta $\mathrm{N}$ using our proposed linear error are identical. The included seven technologies were ranked according to the indices obtained from the application of our new approach and other methods (Borich model, Delta N, and the Modified Delta N methods using our proposed linear factor weight and error), as shown in Table 6. It can be seen from these ranks that the application of our new approach has revealed at the same ranks of the application of the modified Delta N, Delta $\mathrm{N}$ using our proposed linear error, and Borich model for the seven educational technologies included in this study. But there are some differences between these ranks and the ranks obtained from the application of Delta $\mathrm{N}$ using error weights suggested by Misanchuk in 1984. The main reason for such differences is the method of calculating the denominator of the Delta $\mathrm{N}$ equation which was eliminated in the modified Delta $\mathrm{N}$.

Table 5. Final indices obtained from the application of the new approach and the previous methods for training needs assessment.

\begin{tabular}{|c|c|c|c|c|c|c|c|}
\hline \multirow{2}{*}{ ICT } & \multirow{2}{*}{ Borich Model } & \multicolumn{3}{|c|}{ Delta $\mathrm{N}^{*}$} & \multirow{2}{*}{$\begin{array}{l}\text { Delta } N \text { method } \\
\text { (Linear Error } \\
\text { Flat) }\end{array}$} & \multirow{2}{*}{$\begin{array}{l}\text { Modified } \\
\text { Delta (Linear } \\
\text { Error) }\end{array}$} & \multirow{2}{*}{$\begin{array}{l}\text { The New } \\
\text { Approach }\end{array}$} \\
\hline & & Flat & Normal & Monotonic & & & \\
\hline Use of Computer & 4.05 & 0.0112 & -0.0598 & 0.0545 & 0.2054 & 0.6027 & 0.6027 \\
\hline Use of Internet & 3.18 & -0.0130 & -0.0858 & 0.0314 & 0.1642 & 0.5821 & 0.5821 \\
\hline Use of E-mail & 1.64 & -0.0501 & -0.1255 & -0.0041 & 0.0896 & 0.5448 & 0.5448 \\
\hline Use of Word documents & 2.70 & -0.0291 & -0.1030 & 0.0160 & 0.1418 & 0.5709 & 0.5709 \\
\hline Use of Power Point & 2.69 & -0.0340 & -0.1083 & 0.0112 & 0.1418 & 0.5709 & 0.5709 \\
\hline Making Sites & 10.21 & 0.2173 & 0.1611 & 0.2516 & 0.2349 & 0.6175 & 0.6175 \\
\hline Use of Face Book & 0.84 & 0.0367 & -0.0325 & 0.0789 & 0.0597 & 0.5299 & 0.5299 \\
\hline
\end{tabular}

${ }^{*}$ Computed using error weights suggested by Misanchuk [4]. Source: Calculated from data in Appendix.

Table 6. Ranks of the seven educational technologies obtained from the application of the new approach and the previous methods for training needs assessment.

\begin{tabular}{|c|c|c|c|c|c|c|c|}
\hline \multirow{2}{*}{ ICT } & \multirow{2}{*}{ Borich Model } & \multicolumn{3}{|c|}{ Delta $\mathrm{N}^{*}$} & \multirow{2}{*}{$\begin{array}{l}\text { Delta N method } \\
\text { (Linear Error } \\
\text { Flat) }\end{array}$} & \multirow{2}{*}{$\begin{array}{l}\text { Modified } \\
\text { Delta (Linear } \\
\text { Error) }\end{array}$} & \multirow{2}{*}{$\begin{array}{l}\text { The New } \\
\text { Approach }\end{array}$} \\
\hline & & Flat & Normal & Monotonic & & & \\
\hline Use of Computer & 2 & 3 & 3 & 3 & 2 & 2 & 2 \\
\hline Use of Internet & 3 & 4 & 4 & 4 & 3 & 3 & 3 \\
\hline Use of E-mail & 6 & 7 & 7 & 7 & 6 & 6 & 6 \\
\hline Use of Word documents & 4 & 5 & 5 & 5 & 4.5 & 4.5 & 4.5 \\
\hline Use of Power Point & 5 & 6 & 6 & 6 & 4.5 & 4.5 & 4.5 \\
\hline Making Sites & 1 & 1 & 1 & 1 & 1 & 1 & 1 \\
\hline Use of Face Book & 7 & 2 & 2 & 2 & 7 & 7 & 7 \\
\hline
\end{tabular}

Source: Results in Table 5. 


\section{Conclusion}

Without the aid of any assumed probability schemes, we hoped that we succeeded in establishing the basis of a straight forward statistical method for the needs assessment data. The introduced approach is simple. The resultant scale $(0-1)$ is finite and positive. The paper contributes in developing education/training needs assessment methods in the field of education and extension education. Based on the results of the empirical investigation, it is recommended to organize training programs for faculty staff members on the seven educational technologies included according to their rank priorities indicated above to improve the education process at this faculty.

\section{Acknowledgements}

The authors are grateful to:

1. The respectable reviewers of this paper for their valuable comments.

2. Dr. Ahmed B. Abdel-Maksoud for his valuable comments during the preparation of this study.

\section{References}

[1] Mulroy, E.A. (2008) Community Needs Assessment. In: Mizrahi, T. and Davis, L.E., Eds., Encyclopedia of Social Work, 20th Edition, Oxford University Press, New York, 385-387.

[2] McCaslin, N.L. and Tibezinda, J.P. (1998) Assessing Target Group Needs. In: Swanson et al., Eds., Improving Agricultural Extension, a Reference Manual, F. A. O., Rome. http://www.fao.org/docrep/w5830e00.htm

[3] Borich, C.D. (1980) A Needs Assessment Model for Conducting Follow-Up Studies. Journal of Teacher Education, 31, 39-42. http://dx.doi.org/10.1177/002248718003100310

[4] Misanchuk, E.R. (1984) Analysis of Multi-Component Educational and Training Needs. Journal of instructional development, 7, 28-33. http://dx.doi.org/10.1007/BF02905590

[5] Abdel-Maksoud, B.M. (2010) Developing a Modified Delta n Method for Training Needs Assessment. Journal of Agricultural Extension and Rural Development, 2, 133-140.

[6] Misanchuk, E.R. (1987) The Analysis of Multi-Component Educational and Training Needs Data Using The Multivariate Proportionate Reduction in Error Index of Educational Need, Division of Extension and Community Relations. The University of Saskatchewan, Saskatchewan, S7N OWO.

[7] Freund, J.E. (1964) Mathematical Statistics. Prentice-Hall Inc., New Jersey. 


\section{Appendix}

Distribution of respondents according to their evaluation of the degree of importance and their level of knowledge/competence of using the seven educational technologies

(a) Use of Computer

\begin{tabular}{|c|c|c|c|c|c|c|}
\hline \multirow{2}{*}{ Knowledge } & \multicolumn{5}{|c|}{ Importance } & \multirow{2}{*}{ Total } \\
\hline & 1 & 2 & 3 & 4 & 5 & \\
\hline \multicolumn{7}{|l|}{1} \\
\hline 2 & & & & 2 & & 2 \\
\hline 3 & & & & 1 & 12 & 13 \\
\hline 4 & & & & 1 & 26 & 27 \\
\hline 5 & & & & & 25 & 25 \\
\hline Total & & & & 4 & 63 & 67 \\
\hline
\end{tabular}

(b) Internet

\begin{tabular}{cccccc}
\hline & & Importance & & Total \\
\cline { 2 - 3 } Knowledge & 1 & 3 & 4 & 5 & 2 \\
1 & & & & 12 \\
2 & & 2 & 10 & 25 \\
3 & & 2 & 19 & 28 \\
5 & & 6 & 27 & 67 \\
\hline
\end{tabular}

(c) E-mail

\begin{tabular}{|c|c|c|c|c|c|c|}
\hline \multirow{2}{*}{ Knowledge } & \multicolumn{5}{|c|}{ Importance } & \multirow{2}{*}{ Total } \\
\hline & 1 & 2 & 3 & 4 & 5 & \\
\hline 1 & 1 & & & & & 1 \\
\hline 2 & & & 1 & 2 & & 3 \\
\hline 3 & & & 1 & 3 & 7 & 11 \\
\hline 4 & & & 1 & 4 & 11 & 16 \\
\hline 5 & & & 2 & 4 & 30 & 36 \\
\hline Total & 1 & & 5 & 13 & 48 & 67 \\
\hline
\end{tabular}

(d) Word

\begin{tabular}{|c|c|c|c|c|c|c|}
\hline \multirow{2}{*}{ Knowledge } & \multicolumn{5}{|c|}{ Importance } & \multirow{2}{*}{ Total } \\
\hline & 1 & 2 & 3 & 4 & 5 & \\
\hline \multicolumn{7}{|l|}{1} \\
\hline 2 & & & 2 & 0 & 0 & 2 \\
\hline 3 & & & 0 & 6 & 10 & 16 \\
\hline 4 & & & 0 & 4 & 12 & 16 \\
\hline 5 & & & 0 & 2 & 31 & 33 \\
\hline Total & & & 2 & 12 & 53 & 67 \\
\hline
\end{tabular}


B. M. Abdel-Maksoud, S. Saknidy

(e) Power Point

\begin{tabular}{|c|c|c|c|c|c|c|}
\hline \multirow{2}{*}{ Knowledge } & \multicolumn{5}{|c|}{ Importance } & \multirow{2}{*}{ Tota } \\
\hline & 1 & 2 & 3 & 4 & 5 & \\
\hline \multicolumn{7}{|l|}{1} \\
\hline 2 & & & 4 & 1 & 1 & 6 \\
\hline 3 & & & & 3 & 5 & 8 \\
\hline 4 & & & & 5 & 16 & 21 \\
\hline 5 & & & & 0 & 32 & 32 \\
\hline Total & & & 4 & 9 & 54 & 67 \\
\hline \multicolumn{7}{|c|}{ (f) Making Sites } \\
\hline \multirow{2}{*}{ Knowledge } & \multicolumn{6}{|c|}{ Importance } \\
\hline & 1 & 2 & 3 & 4 & 5 & Total \\
\hline 1 & 2 & 1 & 4 & 1 & & 8 \\
\hline 2 & & 2 & 7 & 6 & 1 & 16 \\
\hline 3 & & 1 & 10 & 14 & 6 & 31 \\
\hline 4 & & & & 4 & 5 & 9 \\
\hline 5 & & & & 1 & 2 & 3 \\
\hline Total & 2 & 4 & 21 & 26 & 14 & 67 \\
\hline
\end{tabular}

(g) Face Book

\begin{tabular}{|c|c|c|c|c|c|c|}
\hline \multirow{2}{*}{ Knowledge } & \multicolumn{6}{|c|}{ Importance } \\
\hline & 1 & 2 & 3 & 4 & 5 & Total \\
\hline 1 & 3 & 2 & 2 & & & 7 \\
\hline 2 & & 2 & 6 & & & 8 \\
\hline 3 & 1 & 1 & 7 & 13 & 3 & 25 \\
\hline 4 & & 2 & 1 & 9 & 2 & 14 \\
\hline 5 & & & 2 & 5 & 6 & 13 \\
\hline Total & 4 & 7 & 18 & 27 & 11 & 67 \\
\hline
\end{tabular}

